\title{
Preoperative platelet count in predicting lymph node metastasis and prognosis in patients with non-small cell lung cancer
}

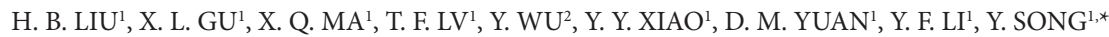 \\ ${ }^{1}$ Department of Respiratory Medicine, Jinling Hospital, Nanjing University School of Medicine, Nanjing, China; ${ }^{2}$ Department of Respiratory \\ Medicine, Jiangsu Province Geriatric Hospital, Jiangsu Province Geriatric Institute, Nanjing, China
}

*Correspondence: yong_song6310@yahoo.com

Received September 1, 2012/ Accepted September 26, 2012

\begin{abstract}
Recent studies have shown an indirect link between platelet count and blood vessel metastasis, but this association with lymphatic vessels metastasis has not been established in NSCLC. So we investigated whether an association exists between preoperative platelet count and lymph node metastasis in NSCLC patients. Between January 2001 and January 2011, platelet counts were obtained from 883 NSCLC patients who were resistant to chemotherapy, radiotherapy, and surgery. The preoperative platelet counts, tumor metastasis, and overall survival of NSCLC patients were analyzed for correlations via statistical analysis. Upon considering patients according to their TNM lymph node metastasis stage (N0-N3), multiple comparison analyses revealed that the mean preoperative platelet count of the N0 group was significantly lower than that of the N1-N3. Analysis of variance showed that the preoperative platelet count of patients in stage I was significantly lower than that of those in stages II, III, and IV, with no significant difference among the latter three stages. According to the Kaplan-Meier survival analysis, the overall survival of patients with platelet counts $<214.5 \times 10^{\%} / \mathrm{L}$ was significantly longer than that of those with platelet counts $\geq 214.5 \times 10^{9} / \mathrm{L}$. Cox regression analysis indicated that, besides preoperative platelet count, patient age, gender, and TNM stage were independent prognostic factors. In conclusion, preoperative platelet count was significantly associated with metastasis of lymph nodes in NSCLC patients. Preoperative platelet count may be a reliable biomarker of lymph node metastasis possibility and an independent prognostic factor of overall survival in patients with NSCLC.
\end{abstract}

Key words: non-small cell lung cancer, preoperative platelet count, lymph nodes, metastasis, prognosis

Among all malignancies, lung cancer has one of the highest rates of mortality [1], often due to metastasis of the primary tumor. Approximately $85 \%$ of patients with lung cancer specifically have non-small cell lung cancer (NSCLC). In most of these, the disease was diagnosed at late and advanced stages $[2,3]$. Metastatic routes of NSCLC are mainly the vascular and lymphatic vessels. Metastasis via the lymphatic vessels usually precedes the vascular, which is occult, and a diagnostic evaluation is difficult for the clinical evaluation. Thus the need is great for biomarkers that indicate or predict metastasis through the lymphatic vessels.

Previous studies have shown that platelet-derived growth factors (PDGFs) are involved in tumor metastasis via the lymphatic system [4-6]. Blood platelet granules are a main storage site of PDGFs, and PDGFs may be released in tumors upon platelet activation and degranulation [7].

In this study we investigated the relation between preoperative platelet count and tumor metastasis in NSCLC, and the values of preoperative platelet count as a prognostic factor of overall survival.

\section{Materials and methods}

Patients and treatment evaluation. The Medical Ethics Committee of Jingling Hospital approved this study. Eight hundred and eighty-three patients with NSCLC that had been diagnosed at Jingling Hospital between January 2001 and January 2011 were enrolled in this study. All final diagnoses were confirmed by pathologic examination. Patients were excluded if they had coexisting health conditions and took medications that could influence platelet count. Such conditions included idiopathic thrombocytopenic purpura and aplastic anemia, among others. None of the enrolled NSCLC patients had any prior chemotherapy, radiotherapy, or surgery.

The clinical stages of the enrolled NSCLC patients ranged from I to IV. Stage assessment was based on computed tomog- 
raphy (CT) scans of the thorax and upper abdomen, magnetic resonance imaging (MRI) scans of the brain, emission CT bone scan, and the pathology report after surgery. The overall survival (OS) of patients was calculated, and 431 patients who are alive at the last follow-up were censored.

Patients were divided into four groups depending on the extent to which cancer cells had spread to regional lymph nodes (N0, N1, N2, and N3), in accordance with the guidelines set by the tumor-node-metastasis (TNM) staging system of the Union for International Cancer Control (UICC; $7^{\text {th }}$ edition) [8].

Table 1. NSCLC patient demographics and clinicopathology.

\begin{tabular}{|c|c|}
\hline Characteristic & Value (\%) \\
\hline Number of patients & 883 \\
\hline \multicolumn{2}{|l|}{ Gender } \\
\hline Male & $615(69.65)$ \\
\hline Female & $268(30.35)$ \\
\hline Median age, years (range) & $18-89(63)$ \\
\hline$<65$ & $485(54.93)$ \\
\hline$\geq 65$ & $398(45.07)$ \\
\hline \multicolumn{2}{|l|}{ Smoking habits (years) } \\
\hline$<20$ & $441(49.94)$ \\
\hline$\geq 20$ & $442(50.06)$ \\
\hline \multicolumn{2}{|l|}{ Histology } \\
\hline Adenocarcinoma & $475(53.79)$ \\
\hline Squamous & $303(34.31)$ \\
\hline Large cell & $8(0.91)$ \\
\hline Other & $97(10.99)$ \\
\hline \multicolumn{2}{|l|}{ TNM Stage } \\
\hline I & $106(12.01)$ \\
\hline II & $78(8.83)$ \\
\hline III & $221(25.03)$ \\
\hline IV & $478(54.13)$ \\
\hline \multicolumn{2}{|l|}{ Pleural effusion } \\
\hline Yes & $133(15.06)$ \\
\hline No & $750(84.94)$ \\
\hline \multicolumn{2}{|l|}{ Metastatic locations } \\
\hline Bone & $190(21.52)$ \\
\hline Brain & $87(9.85)$ \\
\hline Adrenal glands & $14(1.59)$ \\
\hline Lung & $45(5.10)$ \\
\hline Liver & $19(2.15)$ \\
\hline \multicolumn{2}{|l|}{ Distant metastatic organs } \\
\hline No & $405(45.87)$ \\
\hline Yes & $478(54.13)$ \\
\hline Lymph node metastasis & 883 \\
\hline N0 & $248(28.09)$ \\
\hline N1 & $100(11.33)$ \\
\hline $\mathrm{N} 2$ & $379(42.92)$ \\
\hline N3 & $156(17.66)$ \\
\hline \multicolumn{2}{|l|}{ Preoperative platelet counts } \\
\hline$<100 \times 10^{9} / \mathrm{L}$ & $14(1.59)$ \\
\hline $100 \times 10^{9} / \mathrm{L}-300 \times 10^{9} / \mathrm{L}$ & $731(82.79)$ \\
\hline$\geq 300 \times 10^{9} / \mathrm{L}$ & $138(15.62)$ \\
\hline
\end{tabular}

Measurement of platelet count. The platelet count was measured with a hematology analyzer (Sysmex XE2100, Sysmex, Japan) before chemotherapy, radiotherapy, or surgery. (Normal platelet count range is 100 to $300 \times 10^{9} / \mathrm{L}$ ).

Statistical analyses. All statistical analyses were performed with SPSS 17.0 software. Analysis of variance was used to evaluate the significance of mean differences in platelet counts among patients of different metastatic stages. To analyze the association between platelet count and metastasis of either lymph nodes or distant organs, an independent sample $t$-test was performed. To assess the accuracy of using preoperative platelet count as an indicator of lymph node metastasis, a receiver operator characteristic (ROC) curve was constructed. The Kaplan-Meier method was used calculate the survival probability. The log-rank test was performed to assess heterogeneity in survival within each prognostic factor. A Cox regression model was used for analysis of independent prognostic risk factors. A probability $(P)$-value of less than 0.05 was considered significant.

\section{Results}

The characteristics of patients with NSCLC. The mean age of the 883 NSCLC patients enrolled in this study was 63 years (range: 18-89 years) (Table 1). All of these NSCLC patients smoked tobacco, and were equally divided between those who had smoked $<20$ years (441) and those who smoked $\geq 20$ years (442). Histology results revealed that the majority of patients had the NSCLC subtypes adenocarcinoma $(475,53.8 \%)$ or squamous cell carcinoma $(303,34.3 \%)$, and most were either stage III $(221,25 \%)$ or stage IV $(478,54 \%)$. About $15 \%$ of the patients (133) had pleural effusion, and the bone was the main metastatic site (190,21.5\%). More than half of all the patients had distant organ metastases $(478,54.1 \%)$. While the preoperative platelet count in the majority of these patients fell within the normal range $\left([100\right.$ to 300$\left.] \times 10^{9} / \mathrm{L}\right)$, the count was $\geq 300$ $\times 10^{9} / \mathrm{L}$ in $15.62 \%$ (i.e., the patients were thrombocythemic), and in $1.59 \%$ was $<100 \times 10^{9} / \mathrm{L}$.

Preoperative platelet count and lymph nodes metastasis. We first investigated the relation between preoperative platelet counts and the lymph node metastasis. The preoperative platelet counts of the four groups N0-N3 were: N0, 217.55 (standard deviation [SD] 76.36) $\times 10^{9} / \mathrm{L} ; \mathrm{N} 1,237.63(\mathrm{SD} 86.20) \times 10^{9} / \mathrm{L}$; $\mathrm{N} 2,231.31(\mathrm{SD} 89.76) \times 10^{9} / \mathrm{L}$; and N3, $235.98(\mathrm{SD} 81.90) \times$ $10^{9} / \mathrm{L}$. Although combined analysis of variance showed that there was no significant differences in preoperative platelet counts among the four N0-N3 groups $(P=0.074)$, further multiple comparisons revealed that the platelet count of group N0 was significantly lower than that of $\mathrm{N} 1(P=0.045)$, $\mathrm{N} 2(P=0.046)$, and N3 $(P=0.033)$. However, differences in preoperative platelet counts among the N1, N2, and N3 groups were not significant (Table 2).

Preoperative platelet count and TNM stage of NSCLC. Analysis of variance was used to assess the differences in preoperative platelet counts in patients of different TNM stages (I, II, 
III, IV). The mean of the preoperative platelet counts of patients with stages I and II were lower than that of patients with stages III and IV, and the differences were significant among the four stages (Welch statistic $=13.735, P=0.000$; Brown-Forsythe statistic $=10.685, P=0.000$ ). It was found upon further analysis that the preoperative platelet count in stage I patients was significantly lower than that of stages II $(P=0.028)$, III $(P=$ $0.000)$ and IV $(P=0.000)$. However, among stages II, III, and IV, the differences were not significant (Table 3 ).

Preoperative platelet count and prediction of lymph node metastasis. The NSCLC patients were divided into two groups: the 635 patients with lymph node metastasis and the 248 patients without the metastasis. An ROC curve was constructed to assess the accuracy of using preoperative platelet count as an indicator of lymph node metastasis. The area under the curve was 0.557 (95\% confidence interval [CI]: 0.515-0.599). A preoperative platelet count of $214.5 \times 10^{9} / \mathrm{L}$ was chosen as an appropriate cut-off value to predict the metastasis of lymph node with a sensitivity of $53.4 \%$ and a specificity of $56.9 \%$ (Fig. 1); at this cut-off point, the sum of the sensitivity and specificity was the highest.

Table 2. Preoperative platelet counts and lymph node metastasis in patients with NSCLC

\begin{tabular}{|c|c|c|c|c|c|}
\hline Lymph node & $\mathrm{n}$ & Mean $\left(\times 10^{9} / \mathrm{L}\right)$ & $\mathrm{SD}\left(\times 10^{9} / \mathrm{L}\right)$ & Lymph node & $P$ value \\
\hline \multirow[t]{3}{*}{ N0 } & 248 & 217.55 & 76.36 & N1 & 0.045 \\
\hline & & & & $\mathrm{N} 2$ & 0.046 \\
\hline & & & & N3 & 0.033 \\
\hline \multirow[t]{3}{*}{ N1 } & 100 & 237.63 & 86.20 & No & 0.045 \\
\hline & & & & $\mathrm{N} 2$ & 0.506 \\
\hline & & & & N3 & 0.879 \\
\hline \multirow[t]{3}{*}{$\mathrm{N} 2$} & 378 & 231.31 & 89.76 & No & 0.046 \\
\hline & & & & $\mathrm{N} 2$ & 0.506 \\
\hline & & & & $\mathrm{N} 3$ & 0.560 \\
\hline \multirow[t]{3}{*}{ N3 } & 157 & 235.98 & 81.90 & No & 0.033 \\
\hline & & & & $\mathrm{N} 1$ & 0.879 \\
\hline & & & & $\mathrm{N} 2$ & 0.560 \\
\hline
\end{tabular}

Table 3. Preoperative platelet counts and TNM stages in patients with NSCLC

\begin{tabular}{|c|c|c|c|c|c|}
\hline Stage & $\mathrm{n}$ & Mean $\left(\times 10^{9} / \mathrm{L}\right)$ & $\mathrm{SD}\left(\times 10^{9} / \mathrm{L}\right)$ & Stage & $P$ value \\
\hline \multirow[t]{3}{*}{ I } & 106 & 191.79 & 61.92 & II & 0.028 \\
\hline & & & & III & 0.000 \\
\hline & & & & IV & 0.000 \\
\hline \multirow[t]{3}{*}{ II } & 78 & 219.71 & 67.58 & I & 0.028 \\
\hline & & & & III & 0.223 \\
\hline & & & & IV & 0.498 \\
\hline \multirow[t]{3}{*}{ III } & 221 & 240.54 & 99.22 & I & 0.000 \\
\hline & & & & II & 0.223 \\
\hline & & & & IV & 0.926 \\
\hline \multirow[t]{3}{*}{ IV } & 478 & 233.42 & 81.86 & I & 0.000 \\
\hline & & & & II & 0.498 \\
\hline & & & & III & 0.926 \\
\hline
\end{tabular}

Preoperative platelet count and OS. The average OS in the 431 NSCLC patients censored at the last follow-up was 463.8 days. Of these patients, there were 216 whose platelet count was $<214.5 \times 10^{9} / \mathrm{L}$, and their OS was 490.0 days. For the remaining 215 patients whose mean platelet count was $\geq 214.5 \times 10^{9} / \mathrm{L}$, the OS was 437.4 days. The Kaplan-Meier survival analysis showed that the OS of the NSCLC patients whose platelet count was $<214.5 \times 10^{9} / \mathrm{L}$ was significantly longer than that of the NSCLC patients whose platelet count was $\geq 214.5 \times 10^{9} / \mathrm{L}$ (log-rank test, $P=0.042$ ) ( Figure 2). Cox regression analysis found that the following were independent

ROC Curve

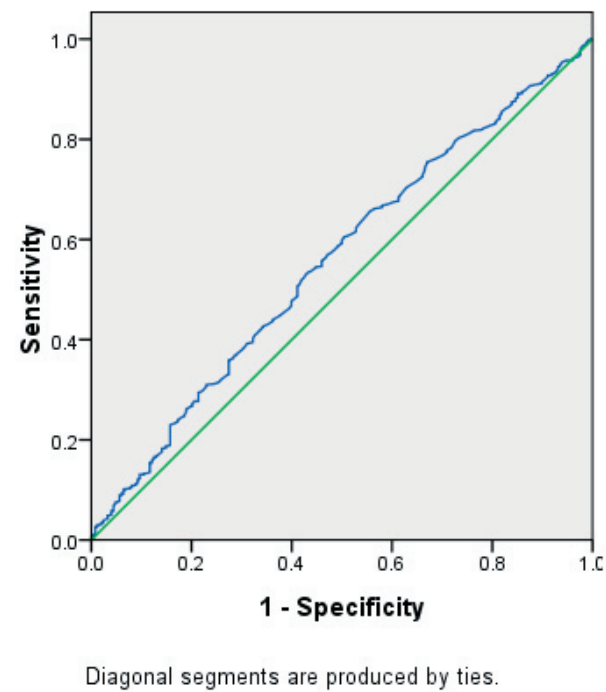

Figure 1. The ROC curves of preoperative platelet count and lymphatic node metastases.

Survival Functions

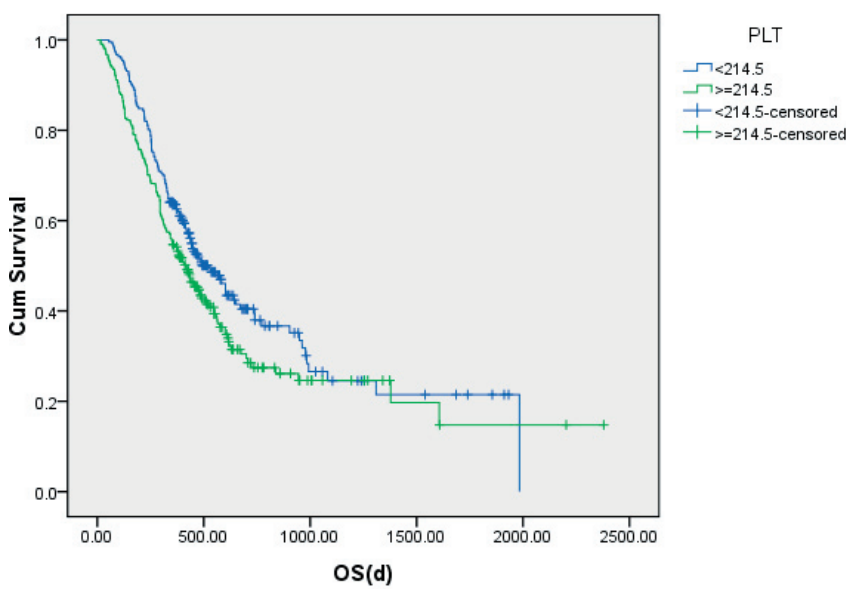

Figure 2. Kaplan-Meier survival analysis of correlation between OS of patients and preoperative platelet counts. 
Table 4. Cox regression analysis of independent risk factors for OS in patients with NSCLC

\begin{tabular}{lcccc}
\hline & P value & HR & \multicolumn{2}{c}{$95.0 \%$ CI for HR } \\
& & & Lower & Upper \\
\hline Gender & 0.022 & 0.685 & 0.495 & 0.947 \\
Age & 0.001 & 1.511 & 1.177 & 1.940 \\
Stage & 0.000 & 1.896 & 1.564 & 2.298 \\
Smoking & 0.176 & 1.226 & 0.912 & 1.647 \\
Histology & 0.592 & 1.047 & 0.885 & 1.238 \\
Platelet & 0.033 & 1.302 & 1.022 & 1.660 \\
\hline
\end{tabular}

prognostic factors in NSCLC patients: age $[P=0.01$, hazard ratio $(\mathrm{HR})=1.511,95 \% \mathrm{CI}: 1.177-1.940]$, gender $(P=0.022$, $\mathrm{HR}=0.685,95 \% \mathrm{CI}: 0.495-0.947), \mathrm{TNM}$ stage $(P=0.000, \mathrm{HR}$ $=1.896,95 \% \mathrm{CI}: 1.564-2.298)$, and preoperative platelet count $(P=0.033, \mathrm{HR}=1.302,95 \% \mathrm{CI}: 1.022-1.660$; Table 4$)$.

\section{Discussion}

In this study, we found that preoperative platelet count was significantly associated with the presence of lymph node metastasis in NSCLC patients, and therefore may be a reliable biomarker of lymph node metastasis. Preoperative platelet count was also an independent prognostic factor of OS in patients with NSCLC.

The association between the preoperative platelet count and lymph node metastasis found in this study is supported by three lines of evidence. Firstly, the platelet count of group N0 was significantly lower than that of N1 $(P=0.045)$, N2 $(P=0.046)$, and N3 $(P=0.033)$, as determined by $t$-test analysis. This agrees with one study in which a univariate analysis showed a significant correlation between preoperative platelet count and lymph node metastasis in patients with colorectal cancer $[9,10]$. Results from the ROC curve constructed for the present study also indicated that the preoperative platelet count might be an indicator of lymph node metastasis. Finally, the platelet count was an independent prognostic factor in NSCLC patients, shown by the Cox regression analysis. This was similarly reported in another study [11]. However, one recent study showed that the preoperative platelet count was not an independent prognostic factor of survival in lung cancer patients [12]. Reasons for the discrepancy between that study and ours are unclear. The differences in statistical methods or patient sample sizes may account for this. Note that the study [12] enrolled a relative small population sample. And our study showed that in addition to the platelet count, age, gender and TNM stage were independent prognostic factors in NSCLC patients. Consistent with this, other reports showed the similar findings [13-15]. For example, using large group of patients, one study demonstrated that clinical stage, age and gender were important prognostic factors for survival in lung cancer [13]. Also, early report using univariate and multivariate analyses in a gender-balanced sample of 152 cases found that the strongest independent factors of NSCLC patient survival were clinical stage, initial weight-loss rate, and gender [15]. These results suggested that these factors may influence on NSCLC outcome.

In a number of cancers, lymphatic vessels were found to be a common route of tumor cells after release from the primary tumor site [16]. Initially it was commonly accepted that there are no peritumoral metastatic lymphatic nodes in the primary tumor. However, recent studies detected lymphatic vessels in certain types of cancers, and additional evidence showed that cancer cells invaded local lymph nodes mainly via peritumoral lymphatic vessels [17-20]. Furthermore, platelets are important in the development of lymphatic vessels. One report found that blood platelets and podoplanin function in the developmental separation of blood and lymphatic circulation in the embryo [21]. Also, platelets synthesize and transport several angiogenic factors such as vascular endothelial growth factor (VEGF), PDGF, and basic fibroblastic growth factor (bFGF) into the blood circulation and tissues [22]; these lymph-angiogenic growth factors were able to stimulate the development of lymphatic vessels via different pathways [23].

Several studies found that thrombocytosis was associated with increased lymphatic involvement in NSCLC and other tumors [24-26]. In our study, a preoperative platelet count below the thrombocytotic range $\left(>300 \times 10^{9} / \mathrm{L}\right.$ in this study) was associated with metastasis of lymph nodes during the early stage of NSCLC. Inhibition of tumor metastasis and reduction of mortality was recently observed in patients treated with low-molecular-weight-heparin, which could be associated with platelet activity, given the known interaction of this drug with these cells $[27,28]$. Our results suggested that reducing platelet counts below the lower limit of thrombocytosis may be associated with reduction of lymph node metastasis during the early stage of NSCLC. More studies were required to confirm this. Other studies [29, 30, 9] used the lower limit of thrombocytosis as the cut-off value to predict OS in several tumors. However, the ROC curve constructed in the present study, based on the lymph node metastases in our NSCLC patients, showed that the more appropriate cut-off value was $214.5 \times 10^{9} / \mathrm{L}$. And the cut-off value $\left(214.5 \times 10^{9} / \mathrm{L}\right)$, which was similar to the average numbers of platelet in stage II. The Table 3 showed that among stages II, III, and IV, the differences of the average numbers of platelet had no significant difference, suggesting that the cut-off value $\left(214.5 \times 10^{9} / \mathrm{L}\right)$ may reflect the different stages to some extent and had less influence on the prognostic outcome in NSCLC patients. However, more studies are needed for further confirmation. Thus, we think that OS in NSCLC patients could be more accurately predicted with a preoperative platelet count cut-off value of $214.5 \times 10^{9} / \mathrm{L}$.

In our study, the sensitivity and the specificity for preoperative platelet count of $214.5 \times 10^{9} / \mathrm{L}$ to predict the metastasis of lymph node were moderate. We think the possible reasons for the not enough high sensitivity and specificity could be due 
to the relative small number of patients without lymph node metastasis compared to that of patietns with lymph node metastasis. Thus, more patient population are needed in th future study in the hope to strengthen our findings. Nevertheless, in addition to using the imaging systems, such as CT, MRI and other known sera markers, preoperative platelet count should be used as an additional new marker to predict the metastasis of lymph node in the clinica arean although more studies are required to confirm.

\section{Conclusions}

The present study show a significant association between preoperative platelet count and lymph node metastasis in the early stage of NSCLC, and thus preoperative platelet count may be a viable biomarker to determine the existence of lymph node metastasis. In addition, preoperative platelet count is an independent prognostic factor in NSCLC patients. A prospective study is required to evaluate further the relation of preoperative platelet count, lymph node metastasis, and progression of NSCLC.

Acknowledgments: This work was supported by the National Natural Science Foundation of China (NO. 81170064) and the Natural Science Foundation of Jiangsu Province (NO. BK2011658).

\section{References}

[1] SIEGEL R, NAISHADHAM D, JEMAL A. Cancer statistics, 2012. CA Cancer J Clin 2012; 62: 10-29. http://dx.doi. org/10.3322/caac. 20138

[2] MOLINA JR, YANG P, CASSIVI SD, SCHILD SE, ADJEI AA. Non-small cell lung cancer: epidemiology, risk factors, treatment, and survivorship. Mayo Clin Proc 2008; 83: 584-594.

[3] WAKELEE HA, BERNARDO P, JOHNSON DH, SCHILLER $\mathrm{JH}$. Changes in the natural history of nonsmall cell lung cancer (NSCLC)--comparison of outcomes and characteristics in patients with advanced NSCLC entered in Eastern Cooperative Oncology Group trials before and after 1990. Cancer 2006; 106: 2208-2217. http://dx.doi.org/10.1002/cncr.21869

[4] CAO Y, ZHONG W. Tumor-derived lymphangiogenic factors and lymphatic metastasis. Biomed Pharmacother 2007; 61: 534-539. http://dx.doi.org/10.1016/j.biopha.2007.08.009

[5] KRZYSTEK-KORPACKA M, DIAKOWSKA D, GAMIAN A, MATUSIEWICZ M. Increase in serum platelet-derived growth factor (PDGF)-BB reflects lymph node involvement in esophageal cancer patients independently from platelet count. Exp Oncol 2011; 33: 140-144.

[6] CAO R, BJORNDAHL MA, RELIGA P, CLASPER S, GARVIN $S$ et al. PDGF-BB induces intratumoral lymphangiogenesis and promotes lymphatic metastasis. Cancer Cell 2004; 6: 333-345. http://dx.doi.org/10.1016/j.ccr.2004.08.034

[7] HELDIN CH, WESTERMARK B. Mechanism of action and in vivo role of platelet-derived growth factor. Physiol Rev 1999; 79: 1283-1316.
[8] SOBIN LH GM, WITTEKIND C. TNM classification of malignant tumors (UICC International Union Against Cancer). 7th ed. Oxford: Wiley-Blackwell 2009.

[9] SASAKI K, KAWAI K, TSUNO NH, SUNAMI E, KITAYAMA J. Impact of preoperative thrombocytosis on the survival of patients with primary colorectal cancer. World J Surg 2012; 36: 192-200. http://dx.doi.org/10.1007/s00268011-1329-7

[10] LIN MS, HUANG JX, ZHU J, SHEN HZ. Elevation of platelet count in patients with colorectal cancer predicts tendency to metastases and poor prognosis. Hepatogastroenterology 2012; 59: 1687-1690. http://dx.doi.org/10.5754/hge12277

[11] GONZALEZ BARCALA FJ, GARCIA PRIM JM, MOLDES RODRIGUEZ M, ALVAREZ FERNANDEZ J, REY REY $\mathrm{MJ}$ et al. Platelet count: association with prognosis in lung cancer. Medical oncology 2010; 27: 357-362. http://dx.doi. org/10.1007/s12032-009-9217-9

[12] CAKAR B, KARAOGLANOGLU M, SAYICI Y, GONULLU DEMIRAG G, YUCEL I. The prognostic value of thrombocytosis in newly diagnosed lung cancer patients: a retrospective analysis. J BUON 2011; 16: 677-681.

[13] SCULIERJP, CHANSKY K, CROWLEY JJ, VAN MEERBEECK J, GOLDSTRAW P. The impact of additional prognostic factors on survival and their relationship with the anatomical extent of disease expressed by the 6th Edition of the TNM Classification of Malignant Tumors and the proposals for the 7th Edition. J Thorac Oncol 2008; 3: 457-466. http://dx.doi. org/10.1097/JTO.0b013e31816de2b8

[14] HSU CP, HSIA JY, CHANG GC, CHUANG CY, SHAI SE et al. Surgical-pathologic factors affect long-term outcomes in stage IB (pT2 N0 M0) non-small cell lung cancer: a heterogeneous disease. J Thorac Cardiovasc Surg 2009; 138: 426-433. http://dx.doi.org/10.1016/j.jtcvs.2008.12.035

[15] PALOMARES MR, SAYRE JW, SHEKAR KC, LILLINGTON LM, CHLEBOWSKI RT. Gender influence on weight-loss pattern and survival of nonsmall cell lung carcinoma patients. Cancer 1996; 78: 2119-2126. http://dx.doi. org/10.1002/(SICI) 1097-0142(19961115)78:10<2119::AIDCNCR12>3.0.CO;2-1

[16] ACHEN MG, STACKER SA. Molecular control of lymphatic metastasis. Ann N Y Acad Sci 2008; 1131: 225-234. http:// dx.doi.org/10.1196/annals.1413.020

[17] ZHANG Z, HELMAN JI, LI LJ. Lymphangiogenesis, lymphatic endothelial cells and lymphatic metastasis in head and neck cancer--a review of mechanisms. Int J Oral Sci 2010; 2: 5-14. http://dx.doi.org/10.4248/IJOS10006

[18] THELEN A, JONAS S, BENCKERT C, WEICHERT W, SCHOTT E et al. Tumor-associated lymphangiogenesis correlates with prognosis after resection of human hepatocellular carcinoma. Ann Surg Oncol 2009; 16: 1222-1230. http://dx.doi.org/10.1245/s10434-009-0380-1

[19] BRITTO AV, SCHENKA AA, MORAES-SCHENKA NG, ALVARENGA M, SHINZATO JY et al. Immunostaining with D2-40 improves evaluation of lymphovascular invasion, but may not predict sentinel lymph node status in early breast cancer. BMC Cancer 2009; 9: 109. http://dx.doi.org/10.1186/ 1471-2407-9-109 
[20] KOUKOURAKIS MI, GIATROMANOLAKI A, SIVRIDIS E, SIMOPOULOS C, GATTER KC et al. LYVE-1 immunohistochemical assessment of lymphangiogenesis in endometrial and lung cancer. J Clin Pathol 2005; 58: 202-206. http://dx.doi. org/10.1136/jcp.2004.019174

[21] UHRIN P, ZAUJEC J, BREUSS JM, OLCAYDU D, CHRENEK $\mathrm{P}$ et al. Novel function for blood platelets and podoplanin in developmental separation of blood and lymphatic circulation. Blood 2010; 115: 3997-4005. http://dx.doi.org/10.1182/blood2009-04-216069

[22] JURASZ P, ALONSO D, CASTRO-BLANCO S, MURAD F, RADOMSKI MW. Generation and role of angiostatin in human platelets. Blood 2003; 102: 3217-3223. http://dx.doi. org/10.1182/blood-2003-02-0378

[23] NAKAYA H, KAWASHIRI S, TANAKA A, NOGUCHI N, KATO K et al. Influences of angiogenesis and lymphangiogenesis on cancerous invasion in experimentally induced tongue carcinoma. J Oral Pathol Med 2005; 34: 87-92. http://dx.doi. org/10.1111/j.1600-0714.2004.00279.x

[24] SAINTIGNY P, KAMBOUCHNER M, LY M, GOMES N, SAINTE-CATHERINE O et al. Vascular endothelial growth factor-C and its receptor VEGFR-3 in non-small-cell lung cancer: concurrent expression in cancer cells from primary tumour and metastatic lymph node. Lung Cancer 2007; 58: 205-213. http://dx.doi.org/10.1016/j.lungcan.2007.06.021

[25] LU CC, CHANG KW, CHOU FC, CHENG CY, LIU CJ. Association of pretreatment thrombocytosis with disease progression and survival in oral squamous cell carcinoma. Oral Oncol 2007; 43: 283-288. http://dx.doi.org/10.1016/ j.oraloncology.2006.03.010

[26] IWASAKI A, KUWAHARA M, YOSHINAGA Y, SHIRAKUSA T. Basic fibroblast growth factor (bFGF) and vascular endothelial growth factor (VEGF) levels, as prognostic indicators in NSCLC. Eur J Cardiothorac Surg 2004; 25: 443-448. http:// dx.doi.org/10.1016/j.ejcts.2003.11.031

[27] KLERK CP, SMORENBURG SM, OTTEN HM, LENSING AW, PRINS MH et al. The effect of low molecular weight heparin on survival in patients with advanced malignancy. J Clin Oncol 2005; 23: 2130-2135. http://dx.doi.org/10.1200/ LCO.2005.03.134

[28] LEE AY, RICKLES FR, JULIAN JA, GENT M, BAKER RI et al. Randomized comparison of low molecular weight heparin and coumarin derivatives on the survival of patients with cancer and venous thromboembolism. J Clin Oncol 2005; 23: 2123-2129.http://dx.doi.org/10.1200/JCO.2005.03.133

[29] AOE K, HIRAKI A, UEOKA H, KIURA K, TABATA M et al. Thrombocytosis as a useful prognostic indicator in patients with lung cancer. Respiration 2004; 71: 170-173. http://dx.doi. org/10.1159/000076679

[30] SHIMADA H, OOHIRA G, OKAZUMI S, MATSUBARA $\mathrm{H}$, NABEYA Y et al. Thrombocytosis associated with poor prognosis in patients with esophageal carcinoma. J Am Coll Surg 2004; 198: 737-741. http://dx.doi.org/10.1016/j.jamcoll surg.2004.01.022 